\title{
Fifty years of cardiothoracic surgery through the looking glass and what the future holds
}

Marko Turina, MD

\section{Those who cannot remember the past are condemned to repeat it. George Santayana}

I thank the Association and its President Craig Miller for the honor of inviting me to address the meeting. I will concentrate on the topic that captivated my interest for many years. Some of you might be skeptical about such a talk, and I do not blame you. We have all sat through the tedious ramblings of elderly surgeons, sometimes coupled with bad jokes, and hoped that their talk would not be too long.

I will try to show you that it is not only interesting but also important to study the history of our profession. One of the famous quotations by Spanish-born American philosopher George Santayana also holds true in our profession: "Those who cannot remember the past are condemned to repeat it.", Forgotten facts can lead to problems in recent innovations, when previous experiences are disregarded by the younger generation. I will mention only 2 recent examples. Parasternal incision for minimally invasive approach to the aortic valve can result in a disturbing and difficult to treat lung herniation. The fact was well known in the 1960s and is only being rediscovered now. Equally important, a proximal coronary stenosis can develop when coronary arteries are cannulated for continuous coronary perfusion. This might cause intimal hyperplasia and lead-in the years after the first operation-to a potentially lethal left main stenosis. This fact was first published in 1976, and I am worried that the newly "rediscovered" method of beating heart valve replacement with direct coronary artery perfusion might lead to the same kind of late complications.

Another lesson from studying the history of our profession is a profound distrust of claim of primacy. It is generally difficult to present something as truly new, as a detailed description of an oxygenator from the Archives of Physiology in 1885 shows. ${ }^{1}$ The device was constructed by 2 physiologists, von Frey and Gruber, for perfusion of isolated organs, but bears uncanny resemblance to the modern heart-lung machines, with temperature and volume control, and a deairing device.

\footnotetext{
From the University of Zurich, Switzerland.

Distinguished guest address, delivered at the 88th Annual Meeting of the American Association for Thoracic Surgery, San Diego, California, May 13, 2008.

Received for publication Aug 14, 2008; accepted for publication Aug 25, 2008.

Address for reprints: Marko Turina, MD, University Hospital, Haldenbach 18, 8091

Zurich, Switzerland (E-mail: marko.turina@usz.ch).

J Thorac Cardiovasc Surg 2008;136:1117-22

$0022-5223 / \$ 34.00$

Copyright (c) 2008 by The American Association for Thoracic Surgery

doi:10.1016/j.jtcvs.2008.08.014
}

\section{IMPORTANCE OF SOCIOECONOMIC CONDITIONS FOR DEVELOPMENT OF CARDIAC SURGERY}

There is a general perception that the development of our profession was made possible by the progress in related sciences, by the discovery of endotracheal intubation and advances in anesthesia, by the discovery of heparin and its rapid reversal by protamine, by the establishment of intensive care units, and by similar developments in related fields. I submit that 2 other aspects were equally important. First, our profession was born and progressed only under socioeconomic conditions favoring innovative development. Second, the birth of cardiac surgery depended on the emergence of courageous, creative pioneers who were willing to apply their experimentally acquired knowledge to clinical practice.

Considerable research in the field of heart surgery was performed in the $1930 \mathrm{~s}$, but socioeconomic conditions were not favorable for the clinical application of revolutionary developments, such as the pump oxygenator. Moreover, the development was dependent on financial support, which faded during turbulent times preceding World War II, with its financial crisis, depression, widespread unemployment, and political upheaval. Two famous men collaborated in the 1930s on the development of a pump oxygenator at Rockefeller Institute in New York: Nobel Prize winner Alexis Carrel and the famous flyer Charles Lindbergh, the first person to fly nonstop across the Atlantic from New York to Paris. Their work was overshadowed by the major economic depression in the United States, gradually involving the whole world, with massive unemployment and social turmoil.

Another example of the profound effect of socioeconomic factors on scientific development can be observed when studying the development of cardiac surgery in the previous Soviet Union. Some important discoveries remained totally unknown in the scientific community because of that country's political isolation, domestic terror, and lack of international contacts. The work of Sergei Sergeevich Brukhonenko, so ably reviewed by Konstantinov and Alexi-Meskishvili, ${ }^{2}$ led to the early development of an oxygenator, first using the autologous lung and from 1936 onward using a bubble oxygenator, which even now looks surprisingly similar to the devices developed 30 years later. This work received no attention and lacked-even in his own country - any clinical impact. The lesson is obvious: Without freedom, scientific development stagnates. Terrible years of purges and gulags in the Soviet Union also exacted a heavy price in science. 


\section{DISAPPEARANCE OF EUROPEAN DOMINANCE IN THE FIELD OF SURGERY}

It is currently forgotten that before World War II, German, British, and French surgical units were considered to be the most advanced, and young aspiring American surgeons usually spent 1 or 2 years in Europe. The reverse happened after World War II, when most of the aspiring European surgeons underwent part of their training in the United States. For example, the late Dr Michael DeBakey, destined to become one of the most prominent cardiac and vascular surgeons in the world, after finishing his surgical training, elected to improve his knowledge by visiting Leriche in Strasbourg and Sauerbruch in Berlin. Dr Alton Ochsner, who later founded this premier institution, Ochsner Clinic in New Orleans, spent a part of his training in Zurich, Switzerland.

The turbulent 1930s witnessed the emergence of totalitarian regimes, with their mass indoctrination, political intolerance, and racial discrimination, which in turn provoked a tremendous brain drain on European science, the United States in particular profiting from this development. During World War II, which exacted not only the tremendous material but also a heavy human cost, the scientific advances in Europe practically seized. The important work of Lawrence $\mathrm{O}^{\prime}$ Shaugnessy ${ }^{3}$ on the surgical treatment of cardiac ischemia, which also led to the formation of the Lambeth Cardiovascular Clinic in London (in the 1930s!), came to the end in the inferno of Dunkirk, during the retreat of the British Army from France in summer of 1940, when O'Shaugnessy was killed by a stray bullet while working on the next edition of his book.

Some important work was performed in safe heavens before or during World War II. Robert Gross's ${ }^{4}$ work in Boston on the closure of patent duct was published in 1939, but his work remained largely unknown to the rest of the world in the turmoil of World War II. Equally revolutionary was Clarence Crawfoord's ${ }^{5}$ resection of coarctation, which he had to submit in 1944 to an obscure Swedish journal, having no other publishing choice. The scientific interaction was interrupted during the war, international mail contact was barely possible, and travel across the Atlantic was risky; one did not attend the meetings or meet the colleagues for an exchange of ideas.

\section{US DOMINANCE IN THE FIELD OF CARDIAC SURGERY}

Emerging victorious and, with the exception of loss of lives in the armed forces, largely unscathed from World War II, the United States entered a period of unprecedented prosperity, which also initiated a period of tremendous advance in science. Dr Blalock achieved world fame with his palliative procedure for tetralogy of Fallot, considered even decades later by many to be almost curative in its effects. After a long preparatory work in the laboratory, the de- velopment of cardiac surgery really began in the 1950s. One of the most extraordinary series of successful operations was performed by the late Dr Lillehei in Minneapolis, using cross-circulation, with an adult, usually a parent of the patient, acting as the circulatory donor. The Minneapolis group used the azygos principle: The patient can be kept alive and survive for a limited period of time on a surprisingly small amount of blood flow of approximately $10 \mathrm{~mL} / \mathrm{kg} / \mathrm{min}$. One should remember that the working conditions in cardiac surgery were extremely primitive in the early 1960s (Figure 1). There was a single-channel oscilloscope for monitoring. Surface-induced hypothermia was used for atrial septal defect closure, using inflow occlusion, which gave exactly 3 minutes to complete the repair and close the atriotomy, the anesthetist being instructed to count 30 -second intervals out loud. Total correction of more complex anomalies was performed in infants with Mohri and colleagues ${ }^{6}$ technique of water-bath cooling until cardiac arrest occurred. The chest was opened-with the infant's body still immersed in cold bath-and the patient was further cooled with gentle cardiac massage to $24^{\circ} \mathrm{C}$ to $25^{\circ} \mathrm{C}$. At this point, the massage was stopped, the quiet heart was opened, and the surgical repair (atrioventricular canal, ventricular septal defect, or transposition of great arteries [TGA]) was performed. Thereafter, the cardiotomy was closed and the patient was rewarmed, first with cardiac massage and later with natural circulation, introducing warm water in the bath and warm saline in the chest.

The rapid introduction of experimental advances into clinical practice led to the marked American dominance in the field of thoracic surgery in the 1960s. All these pioneers, who need no introduction to the audience, led the world in advancing our profession to unprecedented levels. The 1960s were also times of unbridled optimism, with nuclear power promising to be an unlimited source of energy. It is therefore no surprise that nuclear energy was seriously considered for a heart-assist device. Such units were constructed under the Artificial Heart Program in the 1960s and early 1970s, using plutonium 238 as an energy (heat) source and the Sterling steam (!) engine for power conversion. ${ }^{7}$

Much of this progress was made possible, of course, by the generous funding of the National Institutes of Health, which still continues today (Figure 2). This strong financial support led to the American dominance in the field of science, reflected in the statistics of the most quoted articles. US dominance is also visible in the overall statistics of scientific publications. Nobel prizes for science are awarded in the United States with a predictable regularity, although the recent trend ${ }^{8}$ suggests the emergence of Asian scientists (Figure 3).

The late John Kirklin, ${ }^{9}$ in his address to the European Association for Cardiothoracic Surgery in 1990, considered the period from 1954 to 1970 in thoracic surgery as the one of innovation and from 1970 to 1985 as the one of 


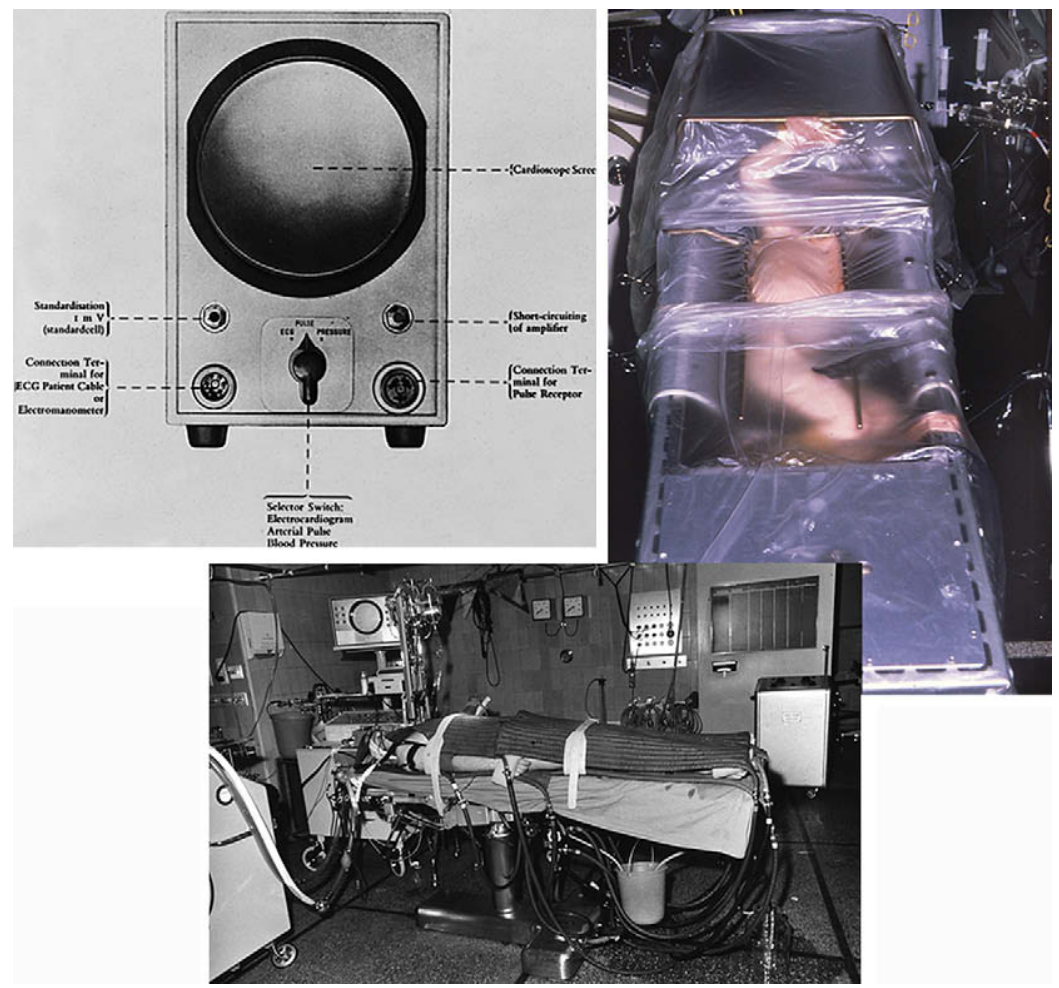

FIGURE 1. Working conditions in the early 1960s: single-channel oscilloscope, surface-induced hypothermia with a rubber blanket for atrial septal defect closure, and total body immersion for deep hypothermia in infants. ECG, Electrocardiogram.

consolidation, and he hoped that the last years of the century would be devoted to scientific development. Few people expected the sudden onset of new developments in our own and related professions, with victorious emergence of percutaneous coronary interventions, which led to the substantial reduction in coronary bypass grafting procedures. Some prominent cardiologists predicted the disappearance of coronary artery bypass grafting for treatment of angina. A side effect of this development is the overall reduction in the number of practicing thoracic surgeons, the difficulties in filling thoracic residencies, and the aging of practicing thoracic surgeons.

\section{EMERGENCE OF NON-US INNOVATIONS IN CARDIAC SURGERY}

Another interesting phenomenon is that for the first time in the short history of our profession, an increasing number of new developments are now taking place outside of the United States. Just as a "pars pro toto" example, the first extensive trials of off-pump coronary artery grafting took place in Argentina and Brazil by Sani and colleagues ${ }^{10}$ and Buffolo and colleagues. ${ }^{11} \mathrm{~A}$ similar trend is presently being observed in the field of percutaneous and transapical valve implantations. It should also not be forgotten that the use of internal thoracic artery and coronary surgery without the use of cardiopulmonary bypass was really pioneered by Vassily Ivanovich Kolessov ${ }^{12}$ in Leningrad in the 1960s.
It is interesting to analyze the reasons for such a shift of scientific advances away from the United States, the country that has dominated the field of thoracic surgery from its very beginning. Several mechanisms might contribute to this phenomenon. First, there is an obvious and increasing amount of governmental interference in the mistaken belief that the population must be "protected" from irresponsible medical and surgical experimentation, a fear happily encouraged by the mass media. Second, we are all increasingly aware of our medical liability and —even worse - of the threat of legal sanctions when one can be found to use an "unproven" method. Third, there is an exceeding pressure by health care providers who are refusing payment for so-called unproven procedures, effectively canceling some of the important recent trials.

The fact remains that the medical liability is becoming a major financial problem, and it acts as a brake on the new developments in surgery. For example, Jatene and colleagues ${ }^{13}$ seminal article of the arterial correction of TGA was published in 1982 and led many of us to change the technique of TGA correction from atrial to arterial switch. In this publication, the observed overall operative mortality was $51 \%$, which was reduced to $17 \%$ in the later part of his series. This was at the time when Dr Mahony's group ${ }^{14}$ in San Francisco (and we in Zurich as well) were achieving zero mortality with atrial correction in infants and newborns. Today, it would be unthinkable to undertake such an effort in 


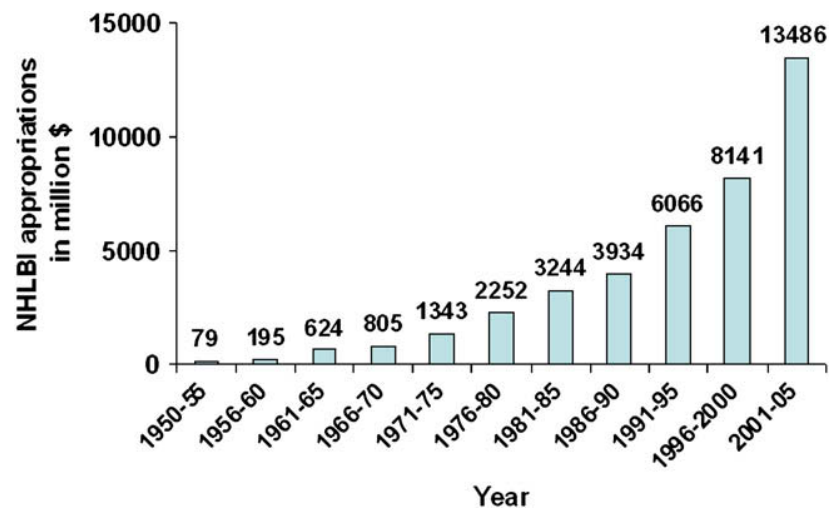

FIGURE 2. National Heart, Lung and Blood Institute research support in the United States in the last 5 decades, in million dollars. National Heart, Lung and Blood Institute (www.nih.gov/about/almanac/appropiations/ index.htm).

North America or Europe: One might lose the license, be struck with monumental damage claims, and even land in jail. Still, it was this courageous work by Jatene and colleagues, which incidentally took place after painstaking anatomic studies, that made us all to move from atrial to arterial correction of TGA, which quickly became the standard method of repair and ushered in the modern era of TGA surgery.

\section{DIFFICULTIES ENCOUNTERED BY THE INNOVATORS}

Our profession obviously depended, and still depends, on courageous innovators. They succeed because they did not accept established dogmas, they did not believe the experts, and they persisted despite widespread criticism. But they did not have it easy! Woodrow Wilson said it succinctly: "If you want to make enemies, try to change something.," Albert Einstein, who also encountered difficulties in his early times, stated that "the great spirits have always encountered violent opposition from mediocre minds." The late Walton Lillehei ${ }^{15}$ made his witty but pertinent comment about the 7 stages of scientific discovery. In the idea stage, it is rejected because it is claimed that it will not work or has been tried before. After successful animal experiments, your critics claim that it will not work in humans. After a first successful clinical application, their only comment is that it is a real tragedy because "now they will continue." After 4 or 5 clinical successes, it is considered by the critics as highly experimental and unethical, and it is whispered that "they have a number of deaths they are not reporting." After 10 to 15 patients, the criticism is still there, with the claim that most of the patients did not need the operation anyway. After a large series of success, your critics will claim that somebody in Shangri-La has been unable to duplicate the results. In the final stage of a scientific discovery, when the method has become established, your critics will

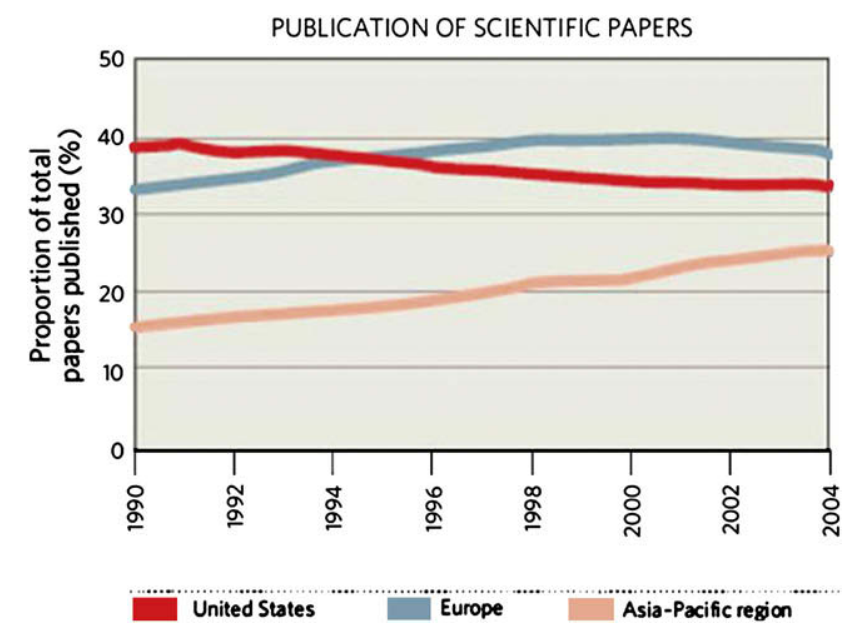

FIGURE 3. World scientific output. With permission from von Bubnoff A. Asia squeezes Europe's lead in science. Nature. 2005;436:314.

state that they had the same idea much earlier, but they did not publish anything and lacked antibiotics, anesthesia, and other technical help. It is obvious that the life of an innovator is not a simple one.

It must be remembered that some of the most important, truly revolutionary work in surgery was violently opposed by its leaders. Ludwig Rehn displayed considerable courage when he performed (and reported) the first suture of the heart wound in 1896. The established opinion, expressed by the leaders of the profession, was that the surgeon who attempts to operate on the heart may be certain to lose the esteem of his or her colleagues forever. It is not quite correctly attributed to Billroth, ${ }^{16}$ the originator of gastric surgery, but it was the predominant opinion at the time when Rehn performed his successful closure of the ventricular perforation. One of the later giants of thoracic surgery, Ferdinand Sauerbruch, explored the idea of operating on the open chest in a spontaneously breathing subject by putting the surgeon and the rest of body in a low-pressure chamber to prevent collapse of the lung. He was forced to stop his experimental work and had to leave his position. In the late 19th and early 20th centuries, our profession, especially in Europe, was dominated by towering personalities who exerted an enormous influence in their field. A classic example of courageous innovation is the pioneering work of Werner Forssmann in heart physiology. He became interested in studying circulation in the right side of the heart and, although forbidden by his chief, he managed to find a nurse to assist him in performing a cut-down on his own cubital vein and to introduce a long urinary catheter into his chest. He then got up, walked a considerable distance to the x-ray department, stood in front of the fluoroscopy screen with a mirror, and advanced the catheter into his right atrium, finishing with an injection of contrast medium. After he published his findings, he lost his job, had to leave 
physiology, was retrained as urologist, and was greatly surprised when he was finally honored-a full 27 years later-by receiving the Nobel prize in medicine.

When observing the work of these great pioneers, I am always reminded of British Prime Minister David Lloyd George's laconic dictum: "Be brave, you cannot cross a chasm in two small jumps." I had the opportunity to work closely with a man who, although not a surgeon, profoundly changed our profession: My charismatic friend, the late Andreas Grüntzig, who never bothered to take his boards in radiology, internal medicine, or cardiology, had the vision to dilate coronary arteries with a self-made, high-pressure balloon. It was indeed impressive to observe a high-grade coronary lesion disappear after a single balloon inflation with a perfectly normal vessel in the consecutive repeat angiographies. It is not well known that the path to success was thorny: In the first series of percutaneous transluminal coronary angioplasty in Zurich, there was a $7.5 \%$ incidence of major life-threatening complications. All of these patients required emergency surgical rescue, sometimes under resuscitation, ${ }^{17}$ and we were proud that not a single patient died of angioplasty complications.

By observing these innovators, several facts become obvious: Being a genius is by itself not sufficient. In addition to purposeful tenacity and single-mindedness, the innovators also need a supportive climate and must be able to deal with inevitable reverses. Even harder to bear is that there might be a substantial human cost in many innovations in our field.

\section{WHICH DIRECTION IS CARDIAC SURGERY GOING?}

We live in a rapidly changing world, so aptly termed the "death of distance" phenomenon (Frances Carrington, The Economist 1997): internationalization of production, tremendous increase in overall mobility, and explosive growth of readily available knowledge. It is equally obvious that the population is rapidly aging, and this phenomenon will soon assume staggering proportion: In the United States alone, 77 million people are expected to be more than 65 years of age by 2040. As a result, the average age of patients who undergo coronary artery bypass grafting is continuously increasing, and we must strive to adjust our techniques accordingly. Another unexpected phenomenon, but the one that has substantial impact on cardiac surgery, is a surprising reduction of cardiovascular mortality, which approaches $50 \%$ in some of the highly developed European countries, Australia, and Canada. This trend has been observed for several decades and is probably a multifactorial event; interestingly enough, there is no change in the mortality of patients with other disease conditions, such as malignancies. It is obvious that the number of coronary artery bypass graft surgeries is continuously decreasing not only because of the reduced incidence of cardiovascular disease but also because of the large-scale application of percutaneous 2coronary interventions.

Patients obviously prefer percutaneous procedures, even with a questionable long-term benefit, and we should listen carefully to this message. We should note what patients currently expect: to undergo a quick, painless procedure with no incision and to leave the hospital the next day at the latest. They do not seem to listen when we try to convince them that our more extensive surgery might offer benefits 3 to 5 years later.

We must observe the tremendous advances in transcatheter endovascular procedures, both in the abdominal and the thoracic aorta, and in peripheral vascular surgery, with impressive control of aneurysm penetration or rupture in elderly patients, who would otherwise be exposed to major operative mortality and morbidity.

It is equally impressive to observe Dr Walther in Dr Mohr's department perform this quick, beating-heart aortic valve replacement by the transapical route without cardiopulmonary bypass and aortic crossclamping, with a perfect hemodynamic result, the elimination of pressure gradient, and well-established coronary perfusion.

\section{DISAPPEARING AREAS OF CARDIAC SURGERY}

We must accept the fact that large areas of cardiac surgery are rapidly disappearing, and we have to adjust our units and training to the changing conditions. It is obvious that we are losing the following:

- A substantial proportion of coronary surgery is being replaced by percutaneous interventions and possibly by the emerging techniques of angiogenesis and related advances in molecular genetics.

- Atrial septal defect and patent ductus arteriosus closure are gone from the surgical repertoire, except as part of the correction of complex anomalies or in very small infants. Transcatheter techniques are firmly established and are being used in increasingly questionable indications.

- Aortic coarctation, both as recurrent and de novo disease, is increasingly being treated with balloon dilatation and covered stents, although long-term observation, especially in unprotected dilatation, is presently lacking.

- Mitral and pulmonary stenosis in the developed nations is not being seen by surgeons: Catheter dilatation has completely taken over the treatment of this condition.

- Arrhythmia surgery (Wolff-Parkinson-White syndrome, ventricular ablation, and atrial flutter) is an established domain of electrophysiologically trained interventionists who have also completely taken over the pacemaker and defibrillator implantations, previously the work of cardiac surgeons. The transcatheter treatment is even being extended to atrial fibrillation, despite reported complications: The last area where surgeons still remain active in 
electrophysiologic procedures is the concomitant open or closed coronary, valve, or congenital heart correction.

- Pulmonary valve replacement is successfully being replaced by the catheter technique, despite some present limitations in the size of the valve that can be implanted via catheter.

- Thoracic aortic aneurysms are rapidly disappearing from the surgical repertoire and are being treated with endovascular procedures. Here, a true benefit is already being observed when applying this minimally invasive, percutaneous approach in aged, polymorbid patients.

- Aortic valve stenosis is currently treated by transfemoral and transapical valve replacement, avoiding the inherent morbidity of cardiopulmonary bypass, aortic manipulation, and prolonged intensive care unit stay: Patients leave the hospital the next day!

- On the horizon is the treatment of mitral incompetence, with various percutaneous procedures. The next few years will bring surprising advances in this field too.

\section{HOW SHOULD CARDIAC SURGERY REACT TO EXTRAORDINARY CHANGES IN THE PROFESSION?}

We should heed the advice of Charles-Maurice de Talleyrand, famous French diplomat of the Napoleonic era: "The art of statesmanship is to foresee the inevitable and to expedite its occurrence." 'Resting on past laurels, quoting our superior long-term surgical results, and adding small changes to our practice (switching to off-pump surgery, applying valve repairs instead of replacement, using total arterial revascularization) are not enough! We must again capture the leadership in cardiac innovations, which we so readily gave away to our colleagues in cardiology and radiology. We must again lead the developments in percutaneous valves and endografts, and arrhythmia procedures. We should explore the possibilities offered by cardiac genomics and applied molecular biology. We should grasp the opportunities offered by the advances in robotics and circulatory assistance. Because surgeons (with rare, honorable exceptions) cannot be basic scientists and competent clinicians at the same time, we should place our highest priority on translational science, enabling rapid and safe application of newly gained knowledge to the care of our patients. To achieve these long-term goals, there is need for an urgent, overdue change in training future thoracic surgeons. As a first step, percutaneous and catheter-based techniques must become part of the curriculum, even if it means spending up to 1 year away from the operating theater. For a strategic objective, we should strive to create our new professional profile: the surgical interventionist, a competent clinician familiar with both open and percutaneous procedures and able to offer the best treatment for his or her patients.

\section{References}

1. Von Frey M, Gruber M. Untersuchungen über den stoffwechsel isolierter organe. Ein respirations-apparat für isolierte organe. Virchows Arch Physiol. 1885;9: 519-32.

2. Konstantinov IE, Alexi-Meskishvili VV, Sergei S. Brukhonenko: the development of the first heart-lung machine for total body perfusion. Ann Thorac Surg. 2000;69:962-6.

3. O'Shaugnessy L. Surgical treatment of cardiac ischemia. Lancet. 1937;232: 185-94.

4. Gross RE. Surgical management of the patent ductus arteriosus with summary of 4 surgically treated cases. Ann Surg. 1939;110:321-5.

5. Crawfoord CL. Tvăfall av kirurgiski behandlad aortastenos. Vetenskappliga förhandligar. 1944;25/11.

6. Mohri H, Dillard DH, Crawford EW, Martin WE, Merendino KA. Method of surface-induced deep hypothermia for open-heart surgery in infants. J Thorac Cardiovasc Surg. 1969;58:262-70.

7. Hughes DA, Faeser RJ, Daly BD, Edmonds CH, Feigenbutz LV, Igo SR, et al. Nuclear-fueled circulatory support systems XII: current status. Trans Am Soc Artif Int Organs. 1974;20:737-46.

8. von Bubnoff A. Asia squeezes Europe's lead in science. Nature. 2005;436:314

9. Kirklin JW. The science of cardiac surgery. Eur J Cardiothorac Surg. 1990;4: 463-71.

10. Sani G, Mariani MA, Benetti F, Lisi G, Maccherini M, Giomarelli P, et al. Coronary surgery without cardiopulmonary bypass. Cardiologia. 1995;40:857-63.

11. Buffolo E, de Andrade CS, Branco JN, Teles CA, Aguiar LF, Gomes WJ. Coronary artery bypass grafting without cardiopulmonary bypass. Ann Thorac Surg. 1996;61:63-6.

12. Kolessov VI. Mammary artery-coronary artery anastomosis as method of treatment for angina pectoris. J Thorac Cardiovasc Surg. 1967;54:535-44.

13. Jatene AD, Fontes VF, Souza LC, Paulista PP, Neto CA, Sousa JE. Anatomic correction of transposition of the great arteries. J Thorac Cardiovasc Surg. 1982;83: 20-6.

14. Mahony L, Turley K, Ebert P, Heymann MA. Long-term results after atrial repair of transposition of the great arteries in early infancy. Circulation. 1982;66:253-8.

15. Lillehei CW. New ideas and their acceptance. As it has related to preservation of chordae tendinea and certain other discoveries. J Heart Valve Dis. 1995;4(Suppl 2):S106-14.

16. Schober KL. More or less devious paths to the heart. On the early history of surgery of the thorax and its organs. Thorac Cardiovasc Surg. 1995;43(Suppl 2): 157-254.

17. Turina M, Grüntzig A, Krayenbühl C, Senning A. The role of the surgeon in percutaneous transluminal dilation of coronary stenosis. Ann Thorac Surg. 1979;28: $103-12$. 